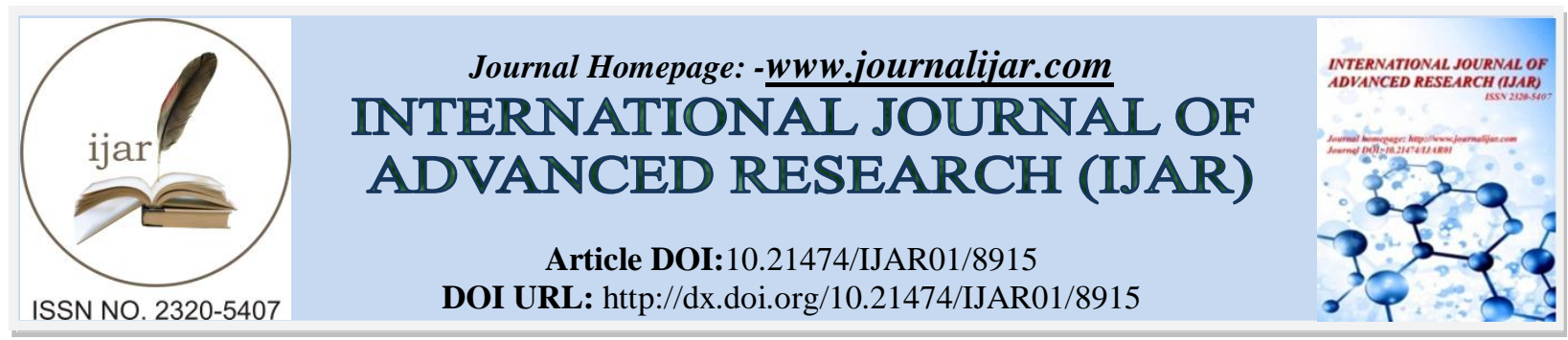

RESEARCH ARTICLE

\title{
SONOGRAPHIC ASSOCIATION OF GALLSTONES WITH FAMILY HISTORY AMONG ADULTS.
}

Muhammad Zubair, Maryam Javed, Ayesha Tariq, Mishel Javaid, Raham Bacha and Syed Amir Gilani. University Institute of Radiological Sciences and Medical Imaging Technologies, Faculty of Allied Health Sciences, University of Lahore, Lahore, Pakistan.

\section{Manuscript Info}

Manuscript History

Received: 20 February 2019

Final Accepted: 22 March 2019

Published: April 2019

Key words:-

Gallbladder, Gallstone disease, Positive history, Negative history.

\section{Abstract}

Background: Gallstones represent a significant burden for health care systems worldwide and are one of the most common disorders presenting to emergency room. The most widely recognized indication of gallstones is right hypochondriac (RHC) or epigastric pain. Ultrasonography are procedure of choice in suspected gallstones. It is most sensitive, specific, non-invasive and inexpensive test for the detection of gallstones.

Objective: To determine the sonographic association of gallstones with family history among adults.

Material and Methods: A cross-sectional study were carried out at the Department of Radiology in Lady Reading Hospital Peshawar, Pakistan. Duration of study were from Feb 2018 to July 27, 2018. All data was analysis by Statistical Software for Social Sciences (SPSS version 24). Mean and standard deviation (SD) were calculated for continuous variables. Frequency and percentages were calculated for categorical variables.

Results: Total 126 were diagnosed and pre-operative cases of gallstone existing in the study. There were $16(12.7 \%)$ men and $110(87.3 \%)$ women. Age ranged from 19 to 80 with mean $43.62 \pm 10.92$ years. RHC or epigastric pain were present in all patients $126(100.0 \%)$. Patients with positive family history of gallstone disease is 45 (35.7\%) and negative family history is $81(64.3 \%)$.

Conclusions: These data suggest that family factors are responsible for at least $35.7 \%$ of symptomatic gallstone disease. However, the true role of heredity in gallstone pathogenesis is probably higher because data based on symptomatic gallbladder disease underestimates the true prevalence in the population.

Copy Right, IJAR, 2019,. All rights reserved.

\section{Introduction:-}

Gallbladder is a gastrointestinal organ situated inside the RHC region of the abdomen. This intraperitoneal, pearmolded sac exists in a fossa framed between the inferior aspects of the right and quadrate lobes of the liver. The primary function of the gallbladder is to focus and store bile, which is produced by the liver. ${ }^{1}$ Gallstone disease (GSD) can be defined as the "presence of one or more stones in the gallbladder" 2 Furthermore, is a standout amongst the most well-known scatters among patients presenting to emergency rooms with abdominal anxiety e.g.,

Corresponding Author:-Muhammad Zubair.

Address:-University Institute of Radiological Sciences and Medical Imaging Technologies, Faculty of Allied Health Sciences. Universitv of Lahore. Lahore. Pakistan. 
RHC or epigastric pain, sickness, vomiting, loss of appetite ${ }^{3}$. Ethnicity and family qualities are perceived as contributing variable ${ }^{3}$. They can happen because of the super immersion of bile, cholesterol precipitation, hindered gallbladder capacity and debilitated of entero-hepatic flow of bile acids ${ }^{5}$.The incident of gallstones sickness is decidedly identified with propelling ages, as gallstones are unordinary in people more youthful than 30 years ${ }^{6}$ usually with the frequency running from $10 \%$ to $20 \%$ of the total populace.Every year around 500,000 cholecystectomies were done in (USA) ${ }^{1}$. The information from Pakistan has observed to be rare, however past examination on southern Sindh zone of Pakistan has revealed a surgical incidence of $9.03 \%$. The frequency of gallstones was discovered numerous folds higher in women when contrasted with men and this expansion was all the more amid childbearing stage. ${ }^{8}$ There are two types of stones, cholesterol stones and shade (pigmented) stones, cholesterol stone are pure saturated fat, mixed stone, combined stone. Pigment stone are black stone, brown stone ${ }^{9}$. Black pigment stones comprise of 7-10\% calcium bilirubinate and brown pigment stones are formed because of disease which change over dissolvable bilirubin into insoluble state prompting development of delicate soft brown stones ${ }^{10}$.

GSD chance elements are multifactorial, which incorporates maturing, sexual orientation, pregnancy, equality, overweight and obesity. Risk factors associated with cholelithiasis in the West include gender $(\mathrm{F}>\mathrm{M})$, age, obesity $^{11,12}$. The risk of disease increases with age interval. It is claimed that females are two times more prone to this disease than males. A well-known reminder for retaining the risk factors corresponded with gallstones is woman, obese, fertile and forty ${ }^{13}$.

In Pakistan, late years has seen an expanding pattern in the quantity of gallstone cases in Southern Sindh, Pakistan ${ }^{14}$, ${ }^{15}$. The recognizable proof of the segments of gallstones is basic as it gives information that could be useful for practitioners to find out the underlying cause of gallstone patients therapeutically or surgically. ${ }^{16}$ Unfortunately, gallstone arrangement is heterogeneous, and varies inside and among the populaces around the world ${ }^{17,18}$.

Ultrasonography is the most sensitive and reasonable test for the exposure of gallstones. It is highly specific and sensitive (>95\%). A characteristics sonographic of gallbladder full of stones will appear wall echo shadowcomplex sign or echogenic mass with shadowing. Because of high echogenicity of the anterior wall of the gallbladder, superficial stones are visible while deeper stones and posterior gallbladder wall are not unmistakable ${ }^{19}$.

Ethics Committee Approval:

This study was approved by scientific Researchers Ethical Committee of The University of Lahore.

Informed Consent:

Written informed was obtain from the participants of this study.

Conflict of Interest:

The authors declared no conflict of interest.

Financial Disclosure:

The authors declared that this study received no financial support.

\section{Inclusion Criteria}

1. All male and female patients having gallstone with certainty family history

2. All normal male and female without gallstones.

\section{Material And Methods:-}

A cross-sectional study were carried out at the Department of Radiology in Lady Reading Hospital Peshawar, Pakistan. Period of study were from Feb 2018 to July 27, 2018. A total of one hundred and twenty six (126) patients were included in the study.

The scanning of gallstones were performed through Mindray DC 70, with frequency range $2.5-3.5$ MHZ. Observations made on gray scale ultrasound machine. 
Descriptive analyses were made to explore the conveyance of data. Mean and standard deviation (SD) were computed for continuous variables. Recurrence and rates were figured for all out factors. All data were analysis by Statistical Software for Social Sciences (SPSS version 24)

\section{Results:-}

There were 126 patients in this study. The Mean Age of patients were $43.62 \pm 10.92$ years. The minimum age were 19 years and the maximum age were 80 years (Table 1 ).

\begin{tabular}{|l|c|c|c|c|c|}
\hline \multicolumn{7}{|c|}{ Descriptive Statistics } \\
\hline & N & Minimum & Maximum & Mean & Std. Deviation \\
\hline Age (Year) & 126 & 19 & 80 & 43.62 & 10.929 \\
\hline Valid N (listwise) & 126 & & & & \\
\hline
\end{tabular}

Table 1:-Descriptive Statistics of Variables

Out of 126 patients, $110(87.3 \%)$ were females and $16(12.7 \%)$ males (Table 2$)$.

\begin{tabular}{|l|r|r|r|r|}
\hline \multicolumn{7}{|c|}{ Gender } \\
\hline female & 110 & 87.3 & \multicolumn{1}{c|}{ Valid Percent } & 87.3 \\
\hline male & 16 & 12.7 & 12.7 & 87.3 \\
\hline Total & 126 & 100.0 & 100.0 & 100.0 \\
\hline
\end{tabular}

Table 2:-Gender wise distribution

69 female and 9 males patients were negative family history while 41 female and 7 males having positive family history (Figure 1).

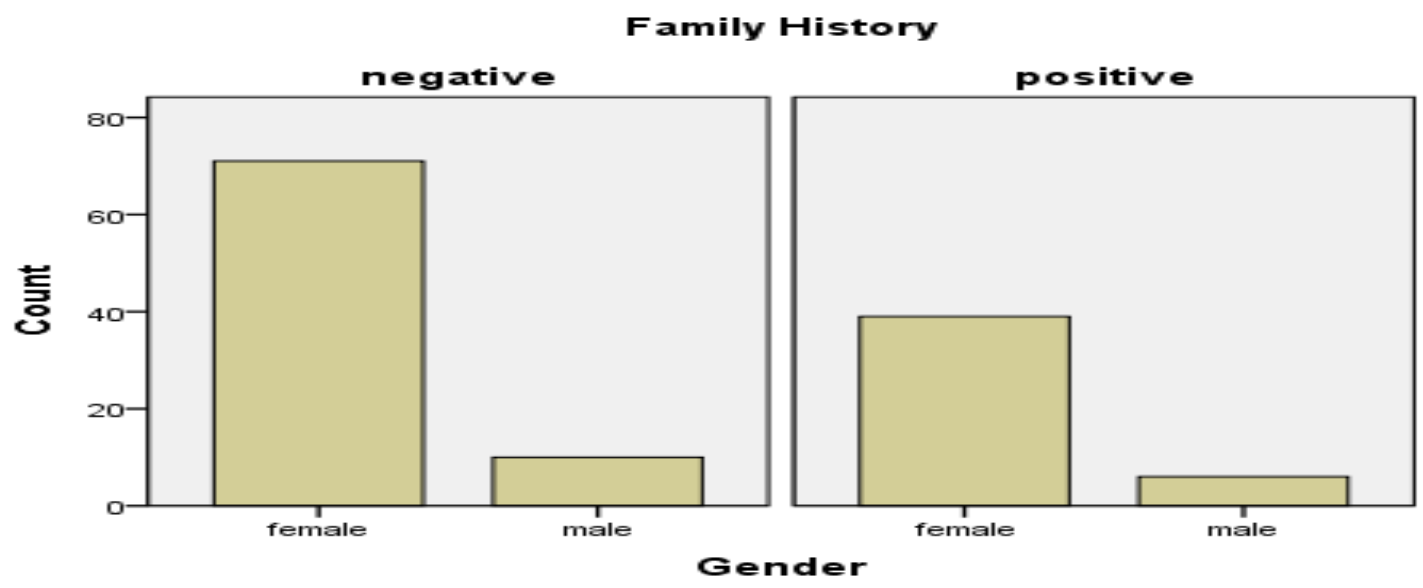

Figure 1:-Gender with family history

According to table 3, Right hypochondriac (RHC) or epigastric pain were present in all patients $126(100.0 \%)$.

\begin{tabular}{|l|r|r|r|r|}
\hline \multicolumn{5}{|c|}{ Right hypochondriac (RHC)/ Epigastric Pain } \\
\hline
\end{tabular}

Table 3:-Symptoms wise distribution

According to figure 2, 81 patients were negative family history and 45 patients were positive family history with right hypochondriac or epigastric pain. 


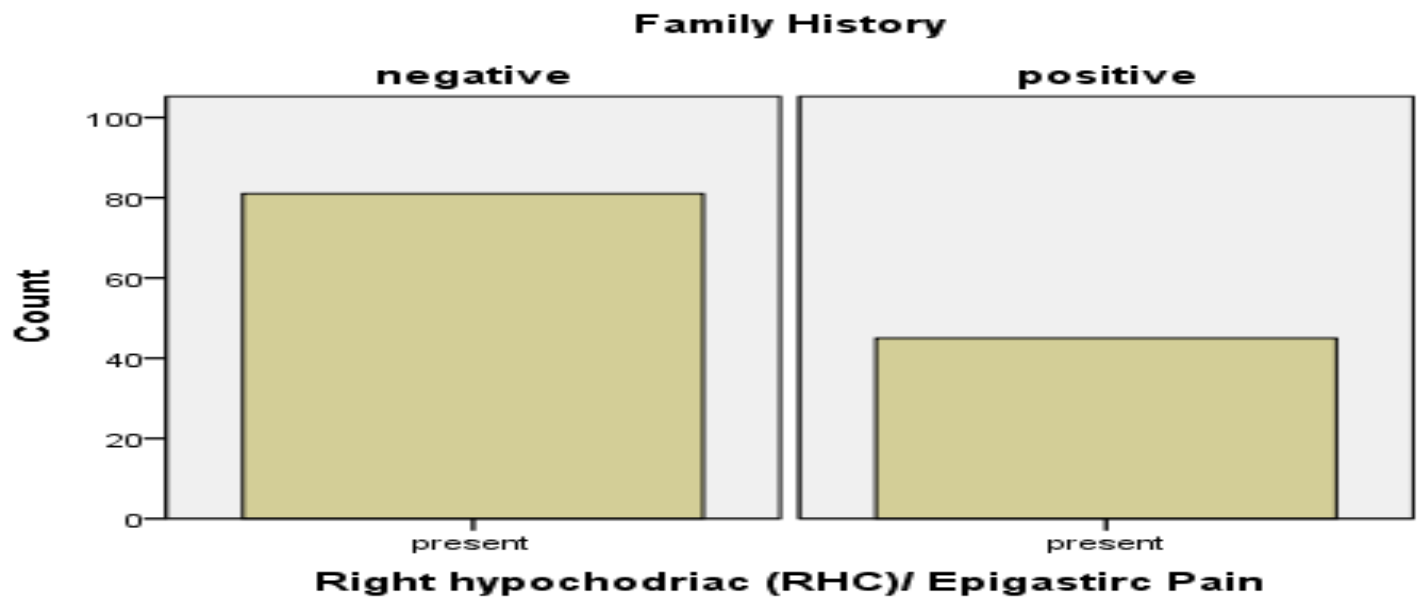

Figure 2:-Family history with Right hypochondriac or epigastric pain

According to table 4, Loss of appetite were present in 13 (10.3\%) patients and absent in 113 (89.7\%) patients out of 126.

\begin{tabular}{|l|r|r|r|r|}
\hline \multicolumn{7}{|c|}{ Loss of appetite } \\
\hline & Frequency & Percent & \multicolumn{1}{c|}{ Valid Percent } & Cumulated Percent \\
\hline absent & 113 & 89.7 & 89.7 & 89.7 \\
\hline present & 13 & 10.3 & 10.3 & 100.0 \\
\hline Total & 126 & 100.0 & 100.0 & \\
\hline
\end{tabular}

Table 4:-Symptoms wise distribution

According to figure 3, 71 patients have no symptom of loss of appetite and 10 patients have symptom of loss of appetite with negative family history and 43 patients having positive family history but no symptom of loss of appetite while 2 patients were symptom of loss of appetite with positive family history.

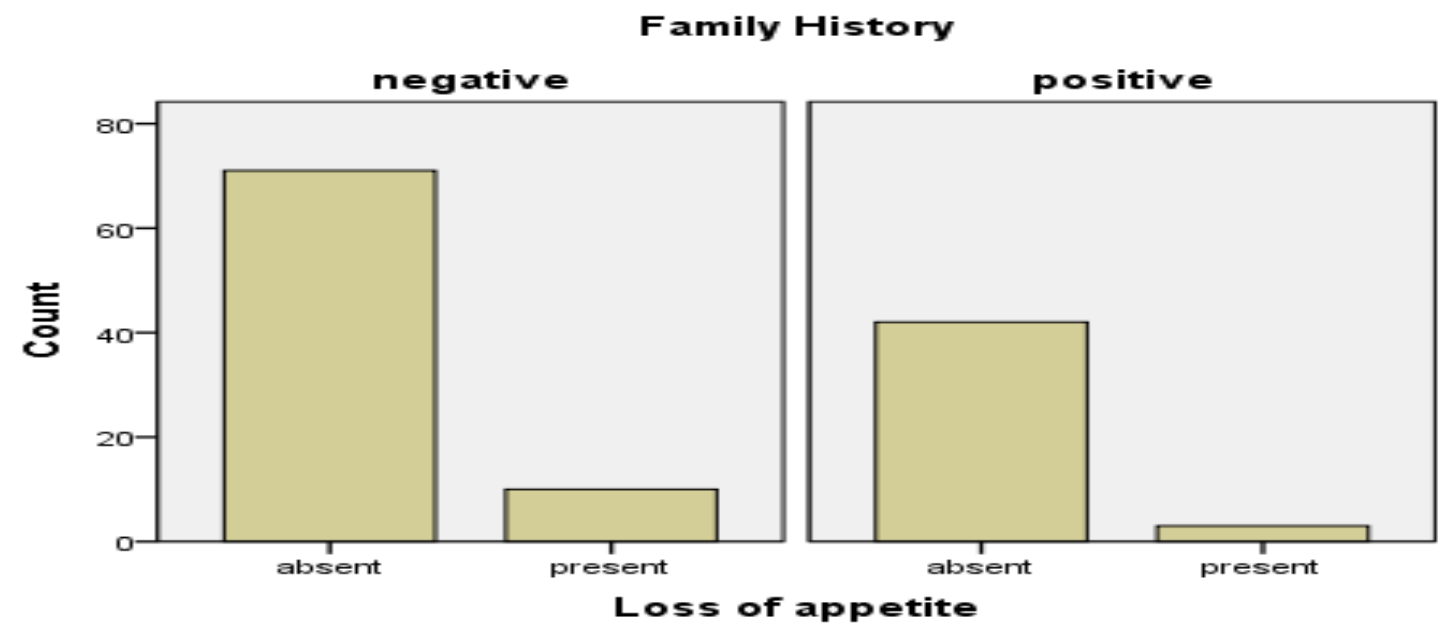

Figure 3:-Loss of appetite with family history

Out of 126 patients, Vomiting/Nausea were present in $105(83.3 \%)$ patients and absent in 21 (16.7\%) patients (Table 5).

\begin{tabular}{|l|r|r|r|r|}
\hline \multicolumn{7}{|c|}{ Vomiting /Nausea } \\
\hline & Frequency & Percent & Valid Percent & Cumulated Percent \\
\hline absent & 21 & 16.7 & 16.7 & 16.7 \\
\hline present & 105 & 83.3 & 83.3 & 100.0 \\
\hline
\end{tabular}




\begin{tabular}{|l|r|r|r|r|}
\hline Total & 126 & 100.0 & 100.0 & \\
\hline
\end{tabular}

Table 5:-Symptoms wise distribution

According to figure 4, 66 patients vomiting/Nausea symptom were present and 15 patients Vomiting/Nausea symptom were absent but patients have negative family history and in 37 patients Vomiting/Nausea symptom were present and 8 patients were absent this symptom patients having positive family history.

Family History

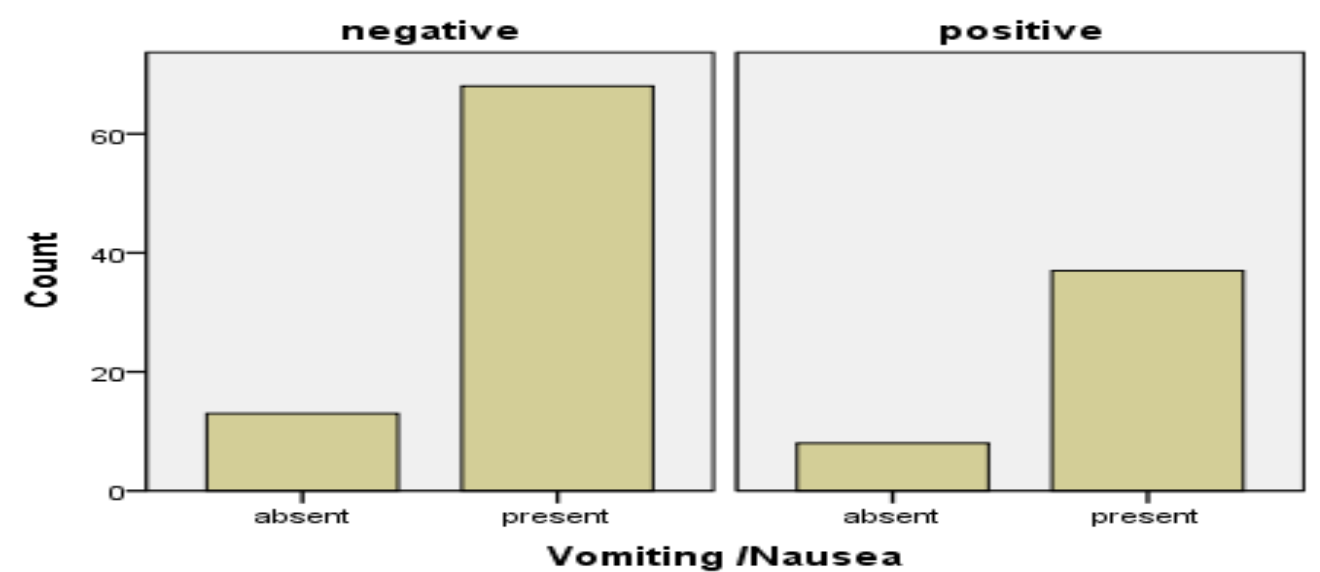

Figure 4:-Vomiting/Nausea with family history

According to table 6 and figure 5,17 patients were no gallbladder stone in which 2 patients have clinically diagnosis while sonographically have no stone with negative history and 15 patients have positive history while 109 patients were gallstone 79 patients have negative history and 30 patients have positive history.

\begin{tabular}{|c|c|c|c|c|}
\hline \multicolumn{5}{|c|}{ Family History * Diagnosis Cross tabulation } \\
\hline & & \multicolumn{2}{|c|}{ Diagnosis } & \multirow[t]{2}{*}{ Total } \\
\hline & & absent & present & \\
\hline \multirow[t]{2}{*}{ Family History } & Negative & 2 & 79 & 81 \\
\hline & Positive & 15 & 30 & 45 \\
\hline \multicolumn{2}{|l|}{ Total } & 17 & 109 & 126 \\
\hline
\end{tabular}

Table 6:-Family history cross tabulation

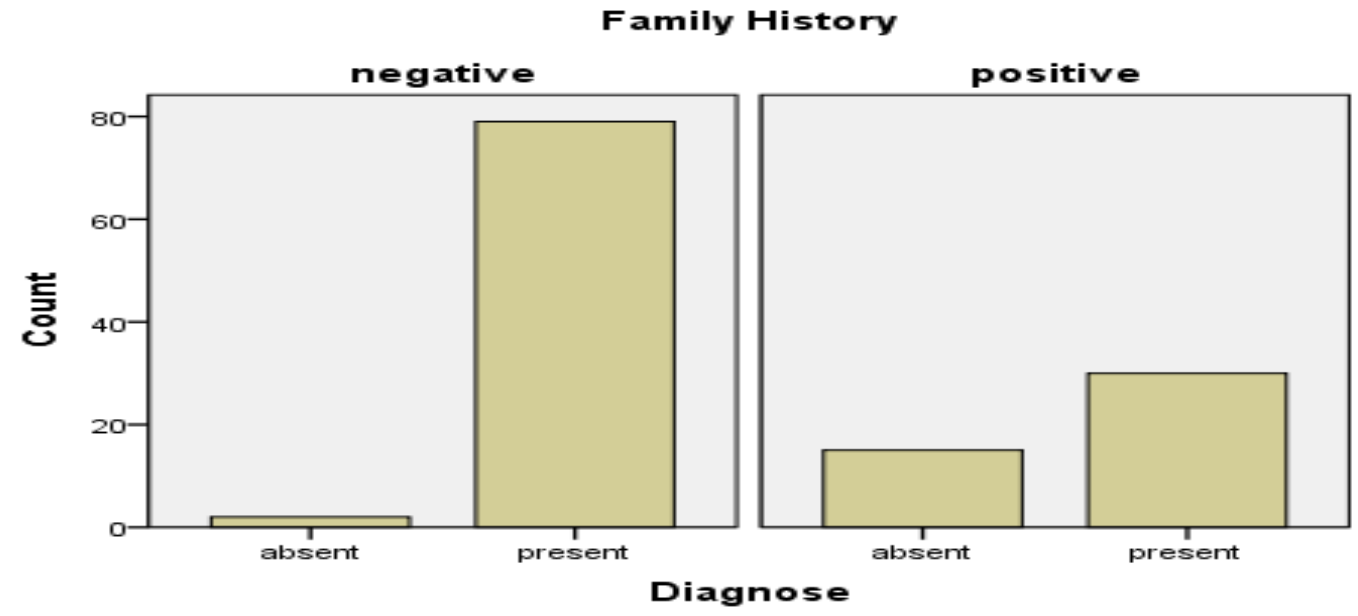

Figure 5:-Family history

According to table 8 , there were $81(64.3 \%)$ patients having negative family history and $45(35.7 \%)$ patients were positive family history total of 126 patients. 


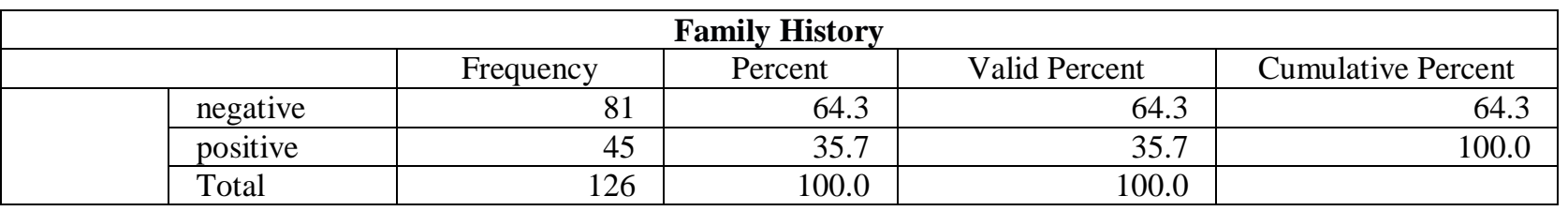

Table 7:-Frequency wise distribution of family history

According to table 9, Out of 126 patients, 17 (13.5\%) patients were absent of gallstones and $109(86.5 \%)$ patients were present of gallstones.

\begin{tabular}{|r|l|r|r|r|r|}
\hline \multicolumn{9}{|c|}{ Diagnosis } \\
\hline \multirow{2}{*}{} & absent & \multicolumn{1}{|c|}{ Frequency } & Percent & Valid Percent & \multicolumn{1}{c|}{ Cumulative Percent } \\
\cline { 2 - 6 } & present & 17 & 13.5 & 13.5 & 13.5 \\
\cline { 2 - 6 } & Total & 109 & 86.5 & 86.5 & 100.0 \\
\hline
\end{tabular}

Table 8: Frequency wise distribution of Diagnosis

\section{Discussion:-}

The current research were designed to determine the sonographic association of gallstones with family history among adults. According to current study the prevalence of gallstones with family history were $35.7 \%$. The results of my study were comparable with the result of the research conducted by Attila Nakeeb et al ${ }^{20}, 2002$ the purpose of his study was control a huge genetic section adds to the pathogenesis of symptomatic gallstones. The outcome demonstrated that the suggestion study major risk factors for symptomatic gallstone sickness were woman gender ( $\mathrm{P}$ $<003)$, obesity $(\mathrm{P}<001)$, age $>50(\mathrm{P}<001)$, and family history of past cholecystectomy in a 1st grade relative $(\mathrm{P}<$ $01)$. In the family examine the added substance genetic heritability of symptomatic gallstones were $29 \%(\mathrm{P}<02)$. Toward the end he reasoned that these data recommend that genetic factors are accountable for at least $30 \%$ of symptomatic gallstone disease. In my study positive family history of gallstone is associated with expanded risk of biliary stone and Ultrasonography is quite often a decent starting decision for distinguishing gallstones in patients experiencing right hypochondriac or epigastric pain.

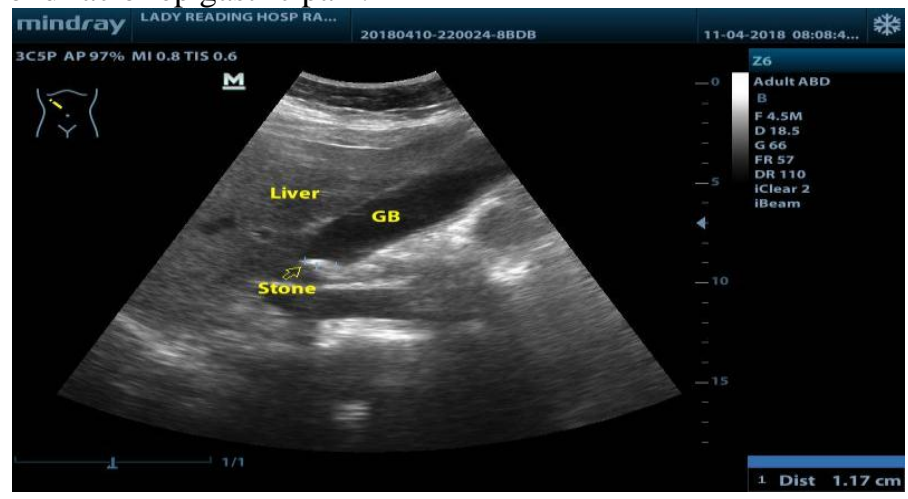

GALLBLADDER STONE

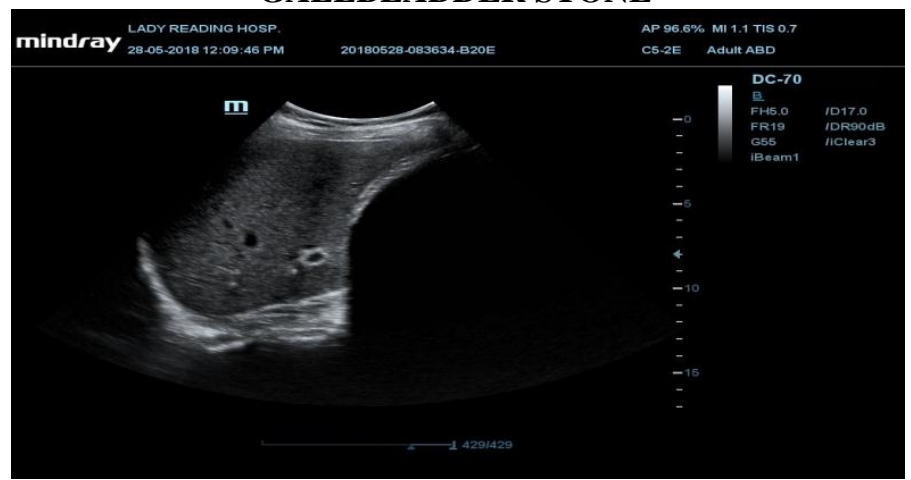

WALL ECHO SHADOW COMPLEX SIGN OF GALLBLADDER 
The result of my study shows that there were very close relation between gallstones and positive family history $35.7 \%$. Ultrasonography is almost always a decent beginning decision and is uncomplicated circumstances, might be all that is required. So my study agrees with the others study that apart from the affectability and specificity of ultrasound, it is non-invasive, readily available, portable and inexpensive. It is therefore justified to use ultrasound as first line modality in the adults to rule out gallstones.

\section{Conclusion:-}

According to this study, females numerous folds higher when contrasted with males and this expansion was all the more amid childbearing age. There were very close relation of gallstones with positive family history.

\section{References:-}

1. Gray H. Anatomy of the human body. 20th edit. Lea \& Febiger, Philadelphia 1918.

2. Bodmer M, Brauchli YB, Krähenbühl S, Jick SS, Meier CR. Statin use and risk of gallstone disease followed by cholecystectomy. Jama 2009;302(18):2001-7.

3. Cirillo DJ, Wallace RB, Rodabough RJ, Greenland P, LaCroix AZ, Limacher MC, et al. Effect of estrogen therapy on gallbladder disease. Jama 2005;293(3):330-9.

4. Wittenburg H, Lammert F. Genetic predisposition to gallbladder stones. In: Seminars in liver disease: Copyright $(2007$ by Thieme Medical Publishers, Inc., 333 Seventh Avenue, New York, NY 10001, USA.; 2007. p. 109-21.

5. Reshetnyak VI. Concept of the pathogenesis and treatment of cholelithiasis. World journal of hepatology 2012;4(2):18.

6. Panpimanmas S, Manmee C. Risk factors for gallstone disease in a Thai population. Journal of epidemiology 2009;19(3):116-21.

7. Idris SA, Shalayel MH, Elsiddig KE, Hamza AA, Hafiz MM. Prevalence of Different Types of Gallstone in Relation to Age in Sudan. Sch. J. App. Med. Sci 2013;1(6):664-7.

8. Ahmad NZ. Routine testing of liver function before and after elective laparoscopic cholecystectomy: is it necessary? JSLS: Journal of the Society of Laparoendoscopic Surgeons 2011;15(1):65.

9. Pradhan S, Joshi M, Vaidya A. Prevalence of different types of gallstone in the patients with cholelithiasis at Kathmandu Medical College, Nepal. Kathmandu University Medical Journal 2009;7(3):268-71.

10. Beckingham I. Gallstone disease. Bmj 2001;322(7278):91-4.

11. Acalovschi M, Buzas C, Radu C, Grigorescu M. Hepatitis C virus infection is a risk factor for gallstone disease: a prospective hospital-based study of patients with chronic viral $\mathrm{C}$ hepatitis. Journal of viral hepatitis 2009;16(12):860-6.

12. Sachdeva S, Khan Z, Ansari MA, Khalique N, Anees A. Lifestyle and gallstone disease: scope for primary prevention. Indian journal of community medicine: official publication of Indian Association of Preventive \& Social Medicine 2011;36(4):263.

13. Chen C-Y, Lu C-L, Lee P-C, Wang S-S, Chang F-Y, Lee S-D. The risk factors for gallstone disease among senior citizens: an Oriental study. Hepato-gastroenterology 1999;46(27):1607-12.

14. Khand F, Ansari A, Khand T. Cholelithiasis in Southern Sindh (Pakistan): Incidence and composition of gallstones. SPECIALIST QUARTERLY-KARACHI- 1997;13:263-70.

15. Channa NA, Khand FD, Bhanger MI, Leghari MH. Surgical incidence of Cholelithiasis in Hyderabad and adjoining areas (Pakistan). Pakistan Journal of Medical Sciences 2004;20(1):13-7.

16. Kratzer W, Mason RA, Kächele V. Prevalence of gallstones in sonographic surveys worldwide. Journal of clinical ultrasound 1999;27(1):1-7.

17. Walker TM, Hambleton IR, Serjeant GR. Gallstones in sickle cell disease: observations from The Jamaican Cohort study. The Journal of pediatrics 2000;136(1):80-5.

18. Akute O, Marinho A, Kalejaiye A, Sogo K. Prevalence of gall stones in a group of antenatal women in Ibadan, Nigeria. African journal of medicine and medical sciences 1999;28(3-4):159-61.

19. Aslam HM, Saleem S, Edhi MM, Shaikh HA, Hafiz M, Saleem M. Assessment of gallstone predictor: comparative analysis of ultrasonographic and biochemical parameters. International archives of medicine 2013;6(1):17.

20. Nakeeb A, Comuzzie AG, Martin L, Sonnenberg GE, Swartz-Basile D, Kissebah AH, et al. Gallstones: genetics versus environment. Annals of surgery 2002;235(6):842. 